\title{
SôBRE O PLÂNCTON DA ENSEADA DO MAR VIRADO E OS MÉTODOS DE COLETAS
}

(Recebido em 11/12/61)

\author{
M. S. de Almeida Prado
}

\begin{abstract}
INTRODUÇÃO
O objetivo dêste trabalho é o estudo do plâncton coletado na enseada do Mar Virado, litoral norte do Estado de São Paulo.

Para o estudo da quantidade e natureza do plâncton foi necessário fazer uma análise dos resultados obtidos com as rêdes de zooplâncton e fitoplâncton, controlando os vários fatôres que influem na eficiência das mesmas.

Êste material forneceu muitas indicações sôbre a região. Estas são, entretanto, relativas apenas aos momentos das coletas, pois as observações não foram suficientemente numerosas para apresentar um quadro geral e definitivo da natureza qualitativa e quantitativa do plâncton da região.
\end{abstract}

\section{MATERIAL E MÉTODOS}

As amostras de plâncton foram tomadas em quatro estações localizadas em quatro pontos dispostos em linha reta e distantes entre si de uma milha náutica (Fig. i) durante os meses de outubro, novembro e dezembro de 1960.

Publ. n. 170 do Inst. Ocean. da USP. 


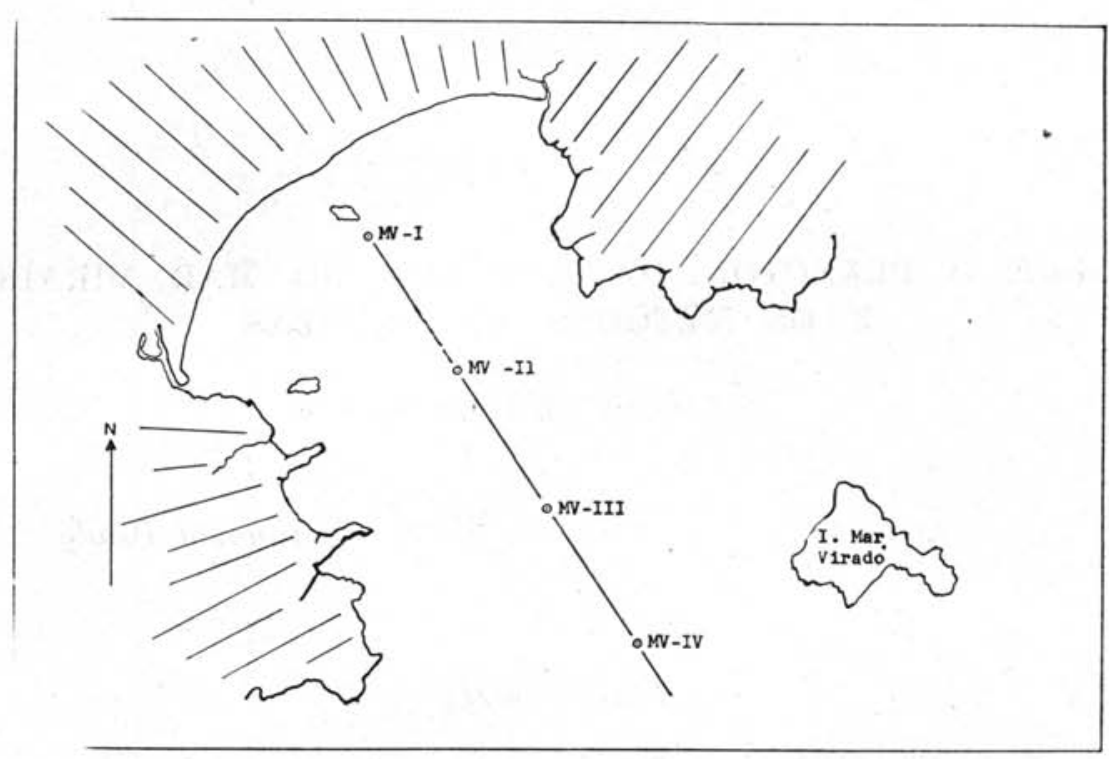

Fig. 1 - Mapa da enseada do Mar Virado (litoral norte do Estado de São Paulo - Brasil).

Durante êsse período, foram coletadas amostras de plâncton quatro vêzes (Tabela I) em cada estação. As coletas foram verticais, utilizando-se duas rêdes de $25 \mathrm{~cm}$ de diâmetro de bôca e $1 \mathrm{~m}$ de comprimento, uma com sêda de 88 malhas por polegada (fitoplâncton) e outra de 58 malhas por polegada (zooplâncton). A análise do material foi baseada em contagens totais de tôdas as amostras.

\section{ASPECTOS HIDROGRÁFICOS DA REGIÃO}

Todos os dados hidrográficos da região aqui citados, foram obtidos de Emilsson (no prelo). Limitar-nos-emos por isso a apresentar alguns aspectos, os mais gerais, necessários para a compreensão dêste trabalho (Tabela I). 


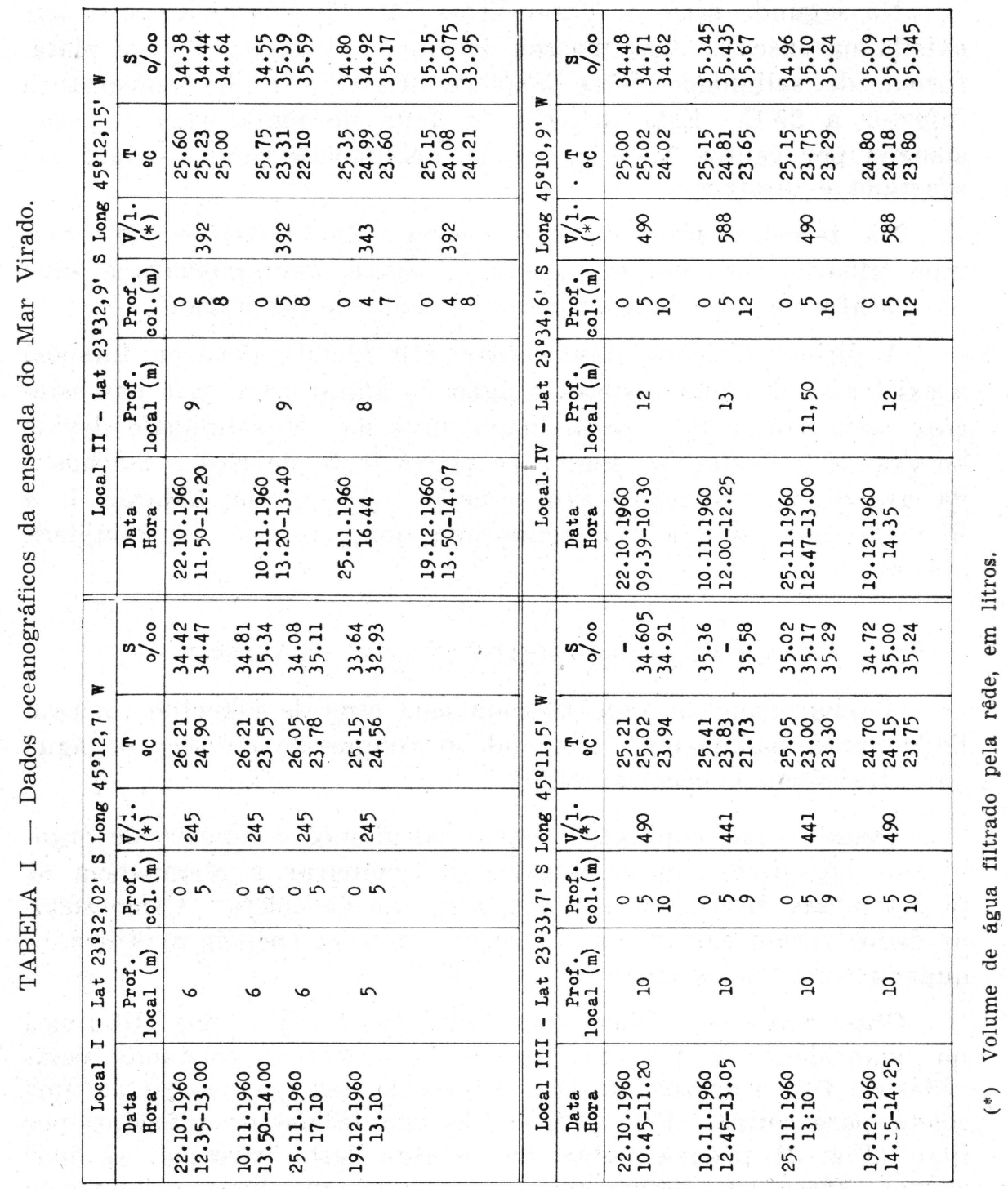


Nas primeiras observações $(22 / 10 / 60)$ constatou-se existir, em tôda a enseada, sòmente água costeira de salinidade inferior a $35,00 \%$ e de temperatura de 24 a $25^{\circ} \mathrm{C}$.

$\mathrm{Na}$ segunda série de observações $(10 / 11 / 60)$ verificou-se que existia na enseada duas massas de água, a costeira e a de plataforma, de salinidade entre 35,00 e $36,00 \%$ e de temperatura inferior a $25^{\circ} \mathrm{C}$. Esta invasão de água de plataforma foi ocasionada por ventos NNE e, como conseqüência disso, a água foi afastada e dissipada.

$\mathrm{Na}$ terceira série de observações $(25 / 11 / 60)$ encontramos uma situação semelhante à anterior, isto é, água costeira e água de plataforma com temperatura variando de 23 a $24^{\circ} \mathrm{C}$.

A última série de observações $(19 / 12 / 60)$ mostrou também a existência de água costeira e água de plataforma, mas nas estações mais próximas à costa houve inversão da salinidade devido ao grande acúmulo de água doce proveniente de rios e riachos e da grande precipitação nessa ocasião. Assim, na Estação I, a $5 \mathrm{~m}$ de profundidade, foi registrada uma redução de salinidade até de $33,00 \%$.

\section{COMPOSIÇÃO QUANTITATIVA DO PLÂNCTON}

A quantidade de água filtrada pela rêde de plâncton foi avaliada aproximadamente, calculando o volume do cilindro de água que atravessou a bôca da rêde.

Baseados nas contagens totais, calculamos o número de organismos por litro, com o objetivo de comparar a abundância de plâncton nas diferentes estações e épocas de coleta. Como todos os dados foram calculados da mesma maneira, podemos utilizá-los quando comparados entre si.

Observamos que houve em tôdas as coletas, uma diferença na quantidade de plâncton, entre as amostras coletadas pelas rêdes de fito e de zooplâncton, diferença essa que variou de uma coleta para outra. Pelo gráfico da quantidade de plâncton por litro (Fig. 2) pode-se notar que, apesar desta variação, as duas curvas, afora em alguns casos, mostram uma mesma tendência geral. Utilizamos os dados obtidos com a rêde de fitoplâncton para avaliar a quantidade de plâncton em cada estação, por várias razões que serão discutidas no próximo capítulo. 


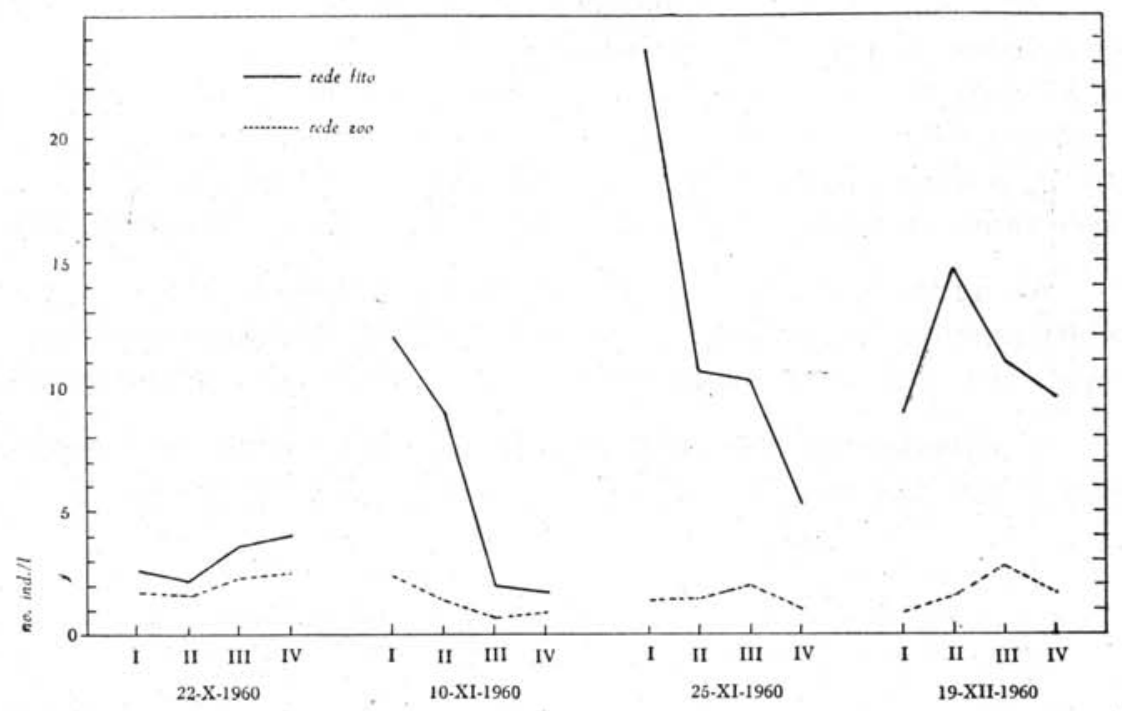

Fig. 2 - Número de organismos por litro encontrados em cada estação.

Na primeira série de coletas, obtivemos uma quantidade de plâncton aproximadamente igual em tôdas as estações. Esta observação coincide com o fato de que a enseada estava naquela ocasião totalmente tomada por uma única massa de água, a costeira.

Na segunda e terceira série de coletas, observamos uma tendência para diminuição da quantidade de plâncton da Estação I para a IV, isto é, da costa para o largo, em sentido contrário ao da introdução da água de plataforma.

Êste gradiente é bem marcado, o que é bem visível nas amostras coletadas com a rêde de fitoplâncton, mesmo que não se leve em consideração as espécies selecionadas positivamente pela rêde de fitoplâncton.

Constatamos, portanto, que as amostras destas duas séries de coletas provenientes de água costeira foram sempre mais ricas do que as da água de paltaforma. 
$\mathrm{Na}$ última série de coletas, obtivemos um gráfico diferente. A amostra de plâncton coletada na Estação I é a mais pobre, provàvelmente devido ao forte abaixamento da salinidade. Nas outras três estações a situação é a mesma das duas séries anteriores, isto é, a quantidade de plâncton diminui da Estação II para a IV, observando sempre as mesmas relações com as massas de água.

As águas costeira e de plataforma na enseada revelaram ser relativamente abundantes, especialmente em algumas espécies de copépodos, em comparação com outras regiões de águas quentes.

O fitoplâncton foi relativamente escasso, tanto em espécies quanto em número de indivídúos, em tôdas as amostras.

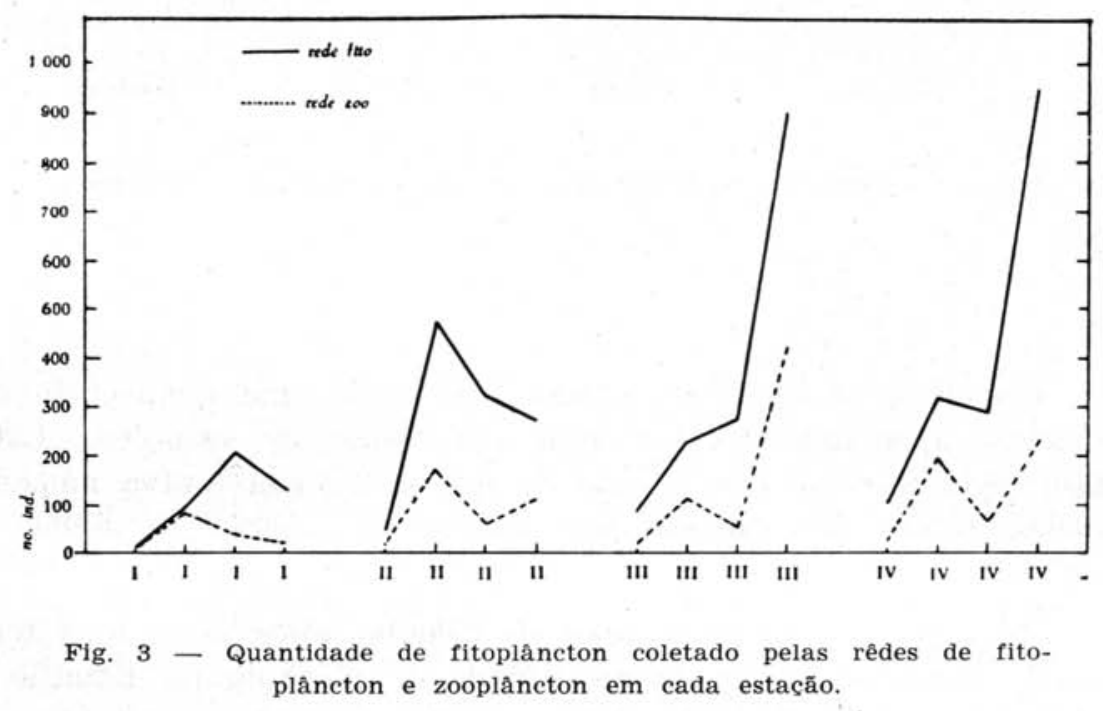

Relacionando a quantidade de fitoplâncton com as diferentes épocas de coleta (Fig. 3), verificamos que êste aumentou da primeira série de coletas para a última. Observamos ainda, que o fitoplâncton foi mais abundante na água de plataforma do que na água costeira. A porcentagem de fitoplâncton variou de 1 a $16 \%$ do total de organismos (Fig. 4) em cada amostra com exceção de uma, em que êste valor atingiu 32,4 em água de plataforma. 


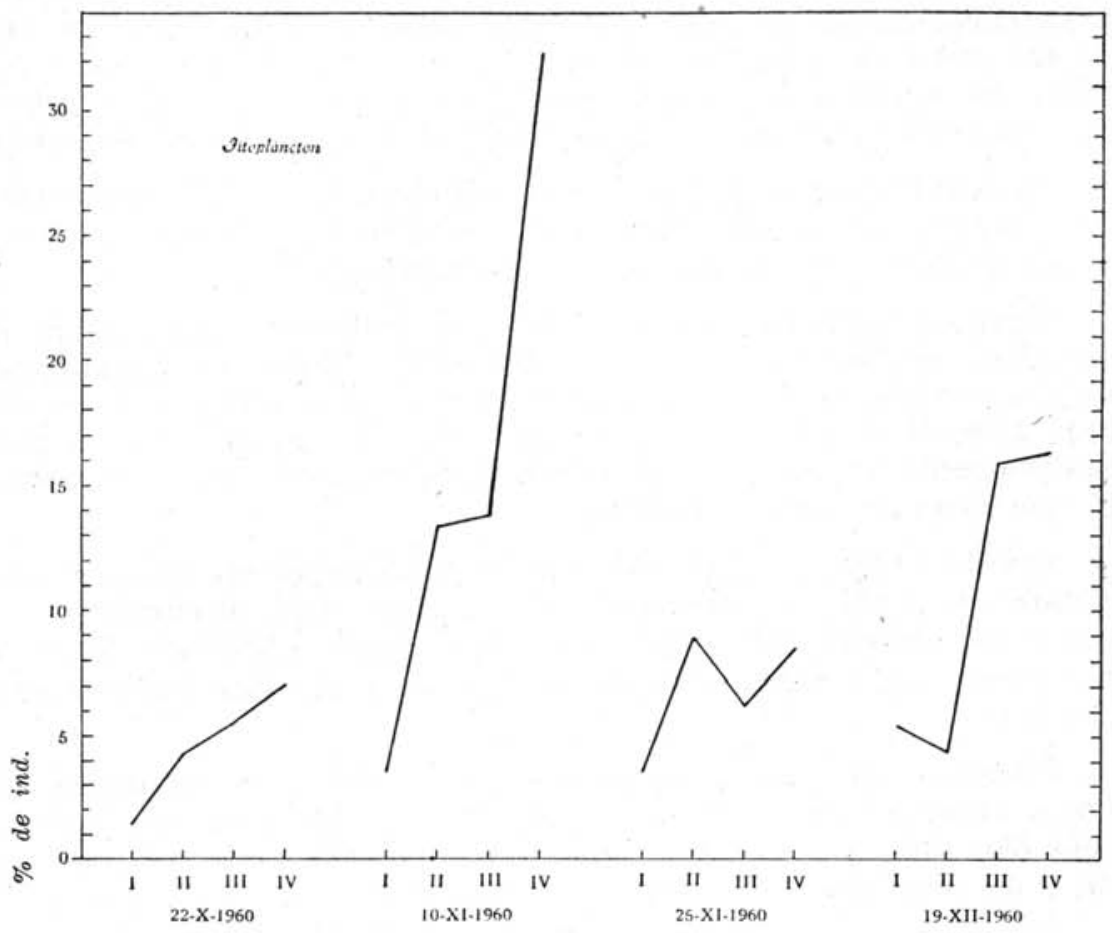

Fig. 4 - Porcentagem numérica de fitoplâncton em relação ao zooplâncton, por amostra em cada estação. 
ANÁLISE COMPARATIVA DAS AMOSTRAS COLETADAS COM REDE DE FITOPLÂNCTON E DE ZOOPLÂNCTON

Os resultados obtidos das amostras de plâncton coletadas com as rêdes de fitoplâncton e de zooplâncton foram sempre muito diferentes. Resolvemos, por isso, fazer uma análise mais pormenorizada dos dados, embora as amostras não tivessem sido coletadas com essa finalidade. Êstes dados, que por si não são suficientes para resolver a questão, são úteis, todavia, por sugerirem que novas experiências deverão ser feitas sôbre a seletividade da malha das rêdes de plâncton. Como a pesquisa sôbre plâncton é baseada, na maioria das vêzes, em observações indiretas, é necessário controlar rigorosamente as limitações dos métodos de coleta.

Vários trabalhos foram feitos sôbre a eficiência das rêdes, raros porém são os que encaram o problema do ponto de vista da seletividade dos organismos pelas malhas.

Segundo Gibbons $(1939$, p. 242) a malha da rêde retem os indivíduos de acôrdo com seus tamanhos. Entre os organismos um pouco menores do que a malha há uma porcentagem dêles que passa através da rêde. Esta porcentagem de escape aumenta progressivamente à medida que diminui o tamanho dos organismos até que nenhum mais é retido.

Saville (1958, p. 193) fêz experimentos especiais sôbre a seletividade da rêde de plâncton. Usou uma rêde de malha mais grossa no interior de outra mais fina, para observar quais os indivíduos que passam através da malha, e em que porcentagem o fazem.

Podemos comparar, embora de uma maneira grosseira, os nossos experimentos com os de Saville $(l . c$.$) , pois não usamos$ como êle, uma rêde dentro de outra, mas puxamos as rêdes de fito e de zooplâncton simultâneamente.

Baseados nos dados obtidos através das duas amostras, fizemos gráficos (Figs. 5 a 12), nos quais relacionamos os números de indivíduos por amostra com as estações, selecionando para êsse fim, as espécies segundo o tamanho médio dos indivíduos em relação ao diâmetro do retículo da malha. Wiborg (1948, p. 6) fêz o mesmo com algumas espécies de copépodos, esclarecendo entretanto, que as medidas devem ser feitas segundo o estágio de desenvolvimento dos animais, e que mesmo assim, estas podem variar com a estação do ano e com a sua procedência.

Para a elaboração dos gráficos neste trabalho, selecionamos três grupos de espécies: as de tamanho menor do que a malha da rêde, as de tamanho um pouco maior e finalmente as de grande porte. 


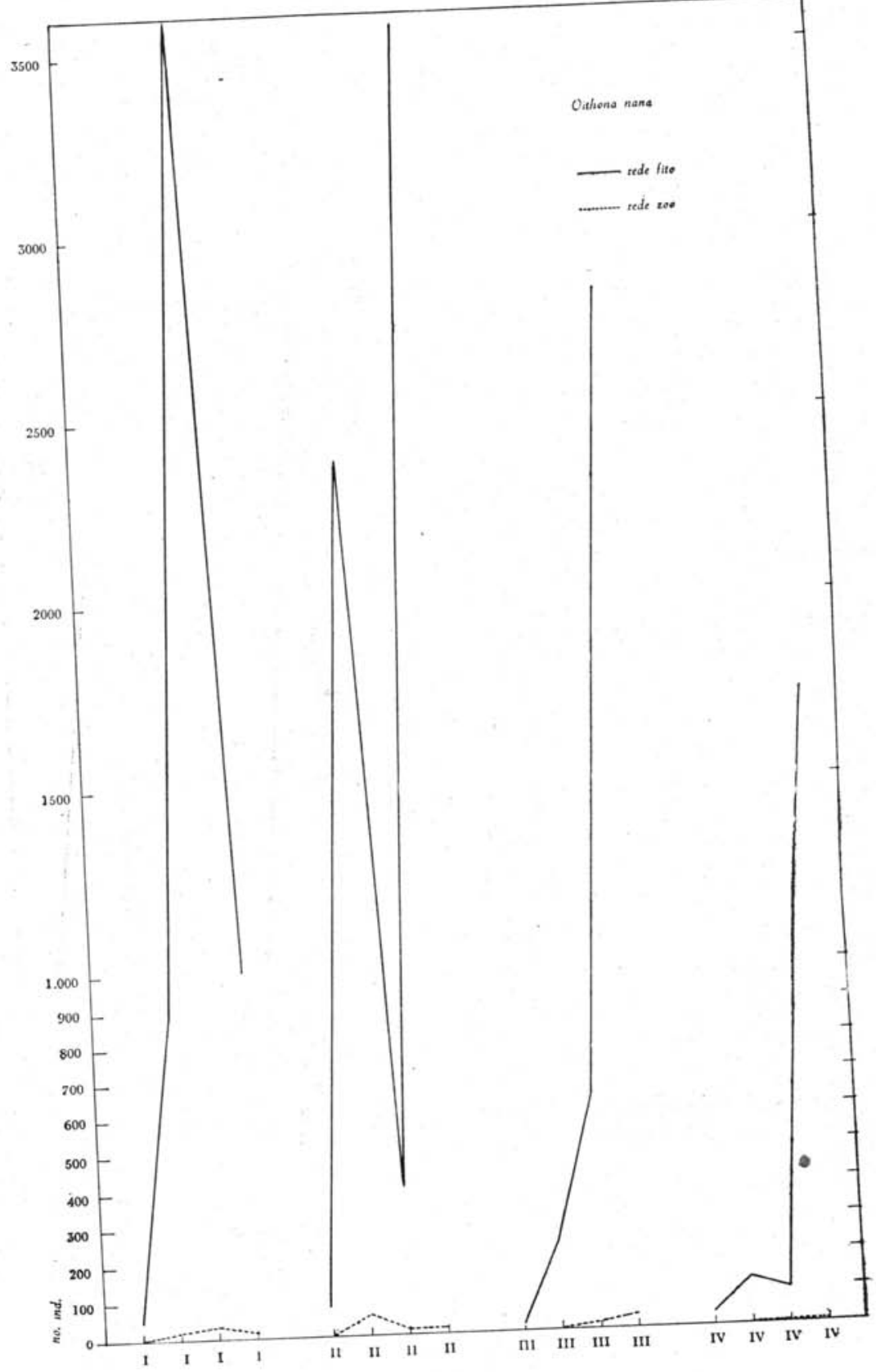

Fig. 5 Quantidade de Oithona nana coletada pelas rêdes de fitoplâncton e zooplâncton em cada estação. 


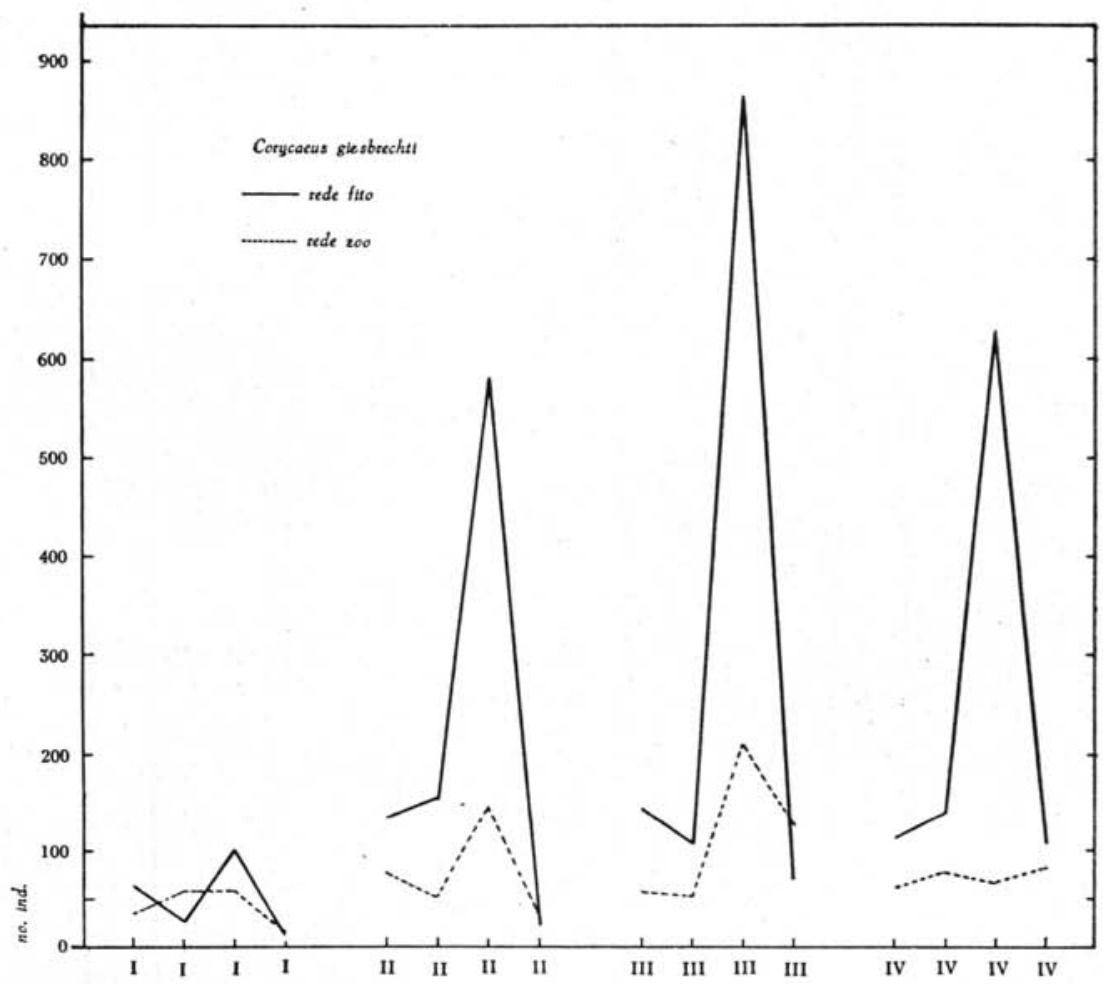

Fig. 6 - Quantidade de Corycaeus giesbrechti coletado pelas rêdes de fitoplâncton e zooplâncton em cada estação. 


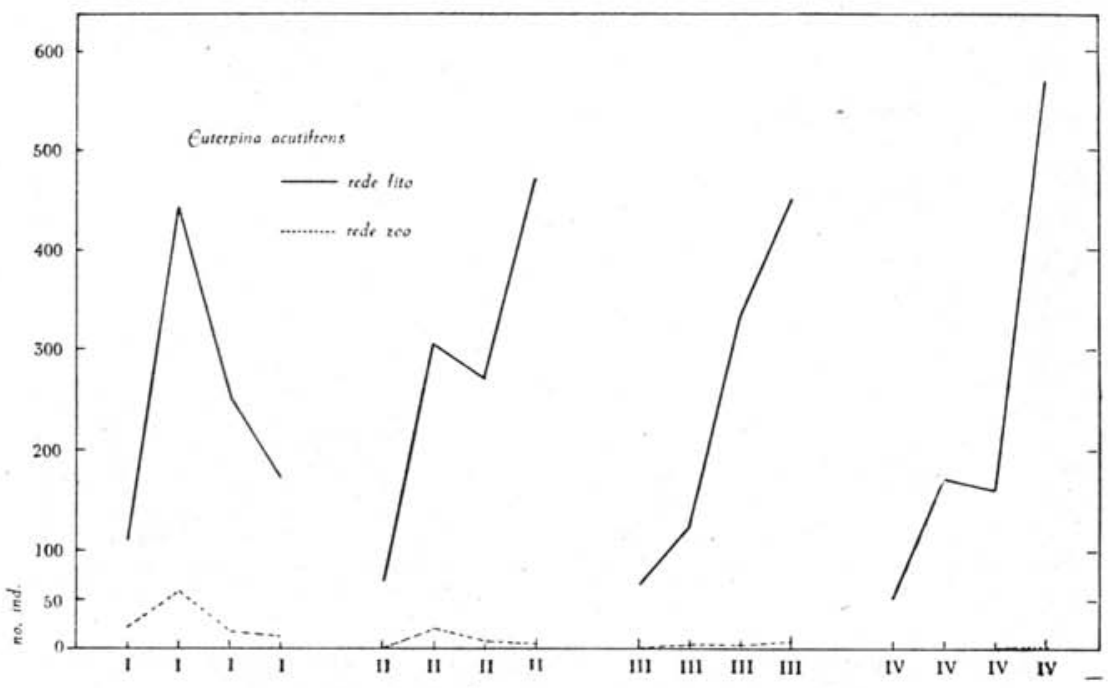

Fig. 7 - Quantidade de Euterpina acutifrons coletada pelas rêdes de fitoplâncton e zooplâncton em cada estação.

Tomamos as medidas das malhas sòmente após a imersão da rêde na água, pois esta encolhe quando molhada (Wiborg, 1948 , p. 6) e por isso, os retículos diminuem. Obtivemos em média $0,1 \mathrm{~mm}$ para rêde de fitoplâncton e $0,3 \mathrm{~mm}$ para a de zooplâncton.

Oithona nana (Fig. 5) foi a espécie escolhida como representante do primeiro grupo, isto é, espécie de tamanho igual ou um pouco menor do que o tamanho da malha da rêde de fitoplâncton.

Fizemos esta escolha por duas razões: primeiro, por que ela foi na maioria das vêzes a espécie mais abundante não só entre os copépodos, como também entre todos os organismos; segundo, por que seus indivíduos possuem em média $0,1 \mathrm{~mm}$ de largura e espessura.

Verificamos por êste gráfico que $O$. nana foi retida em pequeníssima quantidade pela rêde de zooplâncton e em grande quantidade pela rêde de fitoplâncton. Êste fato sugere que a retenção dêsses indivíduos pela rêde de fitoplâncton tenha sido quase completa.

Outras espécies de pequeno porte, tais como Euterpina acutifrons, Corycaeus giesbrechti apresentaram um comportamento semelhante ao de $O$. nana, porém $C$. giesbrechti foi mais retido pela rêde de zooplâncton do que as outras duas espécies. 


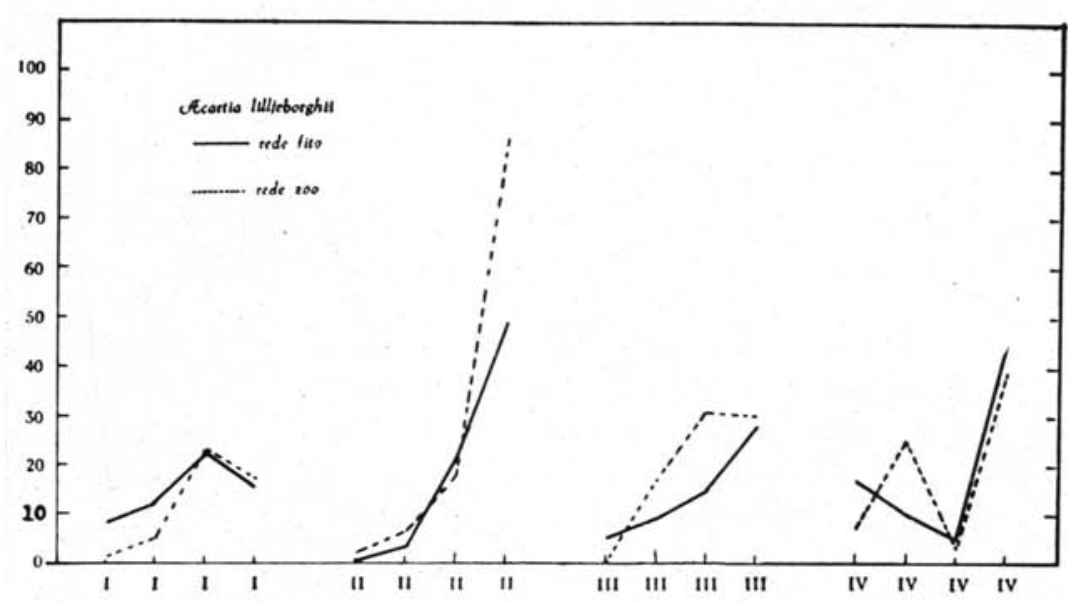

Fig. 8 - Quantidade de Acartia lilljeborghi coletada pelas rêdes de fitoplâncton e zooplâncton em cada estação.

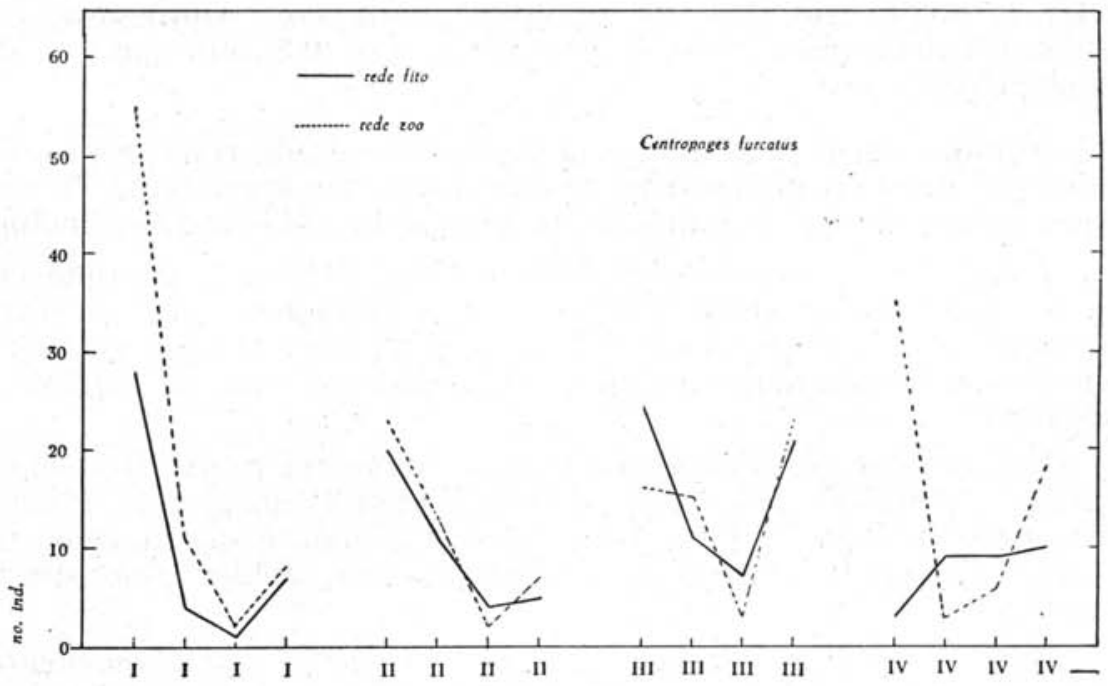

Fig. 9 - Quantidade de Centropages furcatus coletado pelas rêdes de fitoplâncton e zooplâncton em cada estação. 


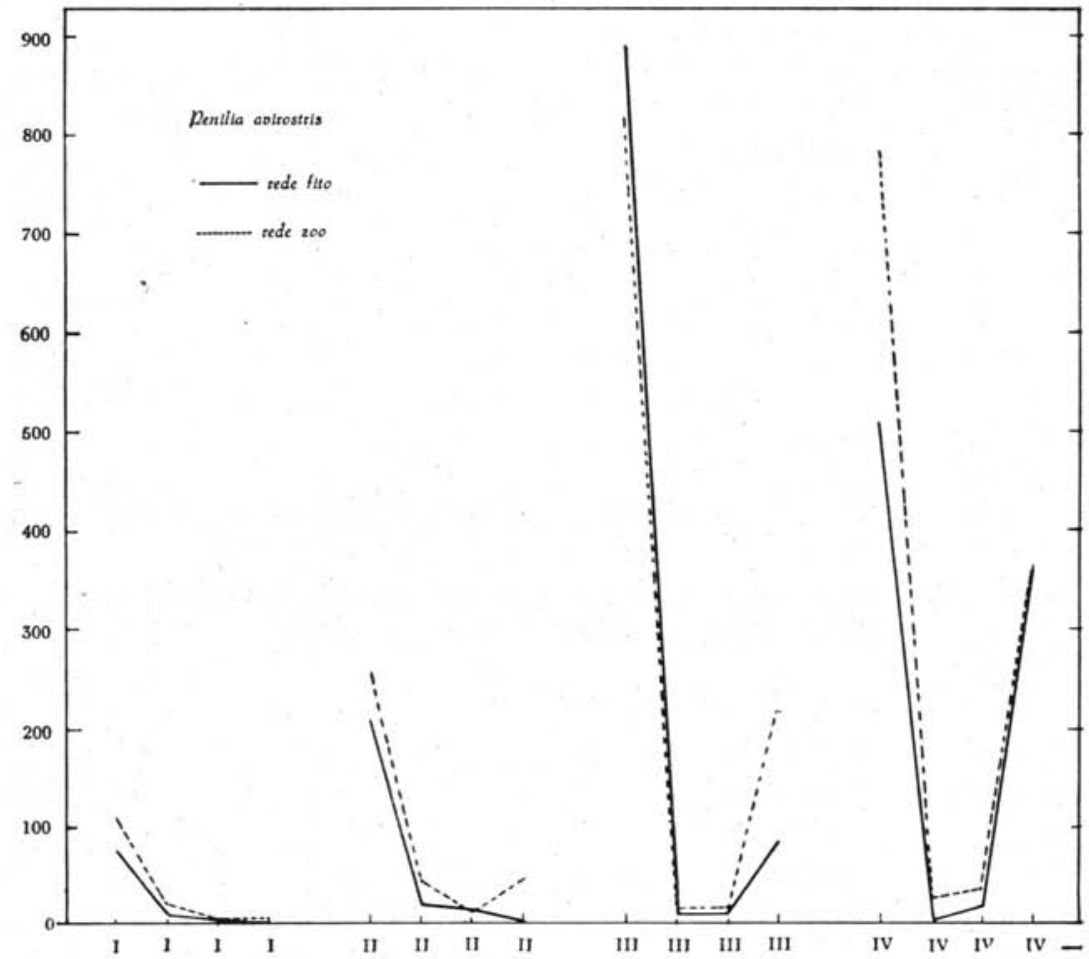

Fig. 10 - Quantidade de Penilia avirostris coletada pelas rêdes de fitoplâncton e zooplâncton em cada estação. 
Espécies de diâmetro maior do que o tamanho da malha da rêde de fitoplâncton, como Acartia lilljeborghi, Centropages furcatus e Penilia avirostris não revelaram no conjunto uma apreciável discrepância entre as duas coletas. As diferenças numéricas dessas espécies, entre as amostras coletadas com rêde de fitoplâncton e zooplâncton, podem ser atribuidas às pequenas aglomerações de indivíduos durante a coleta.

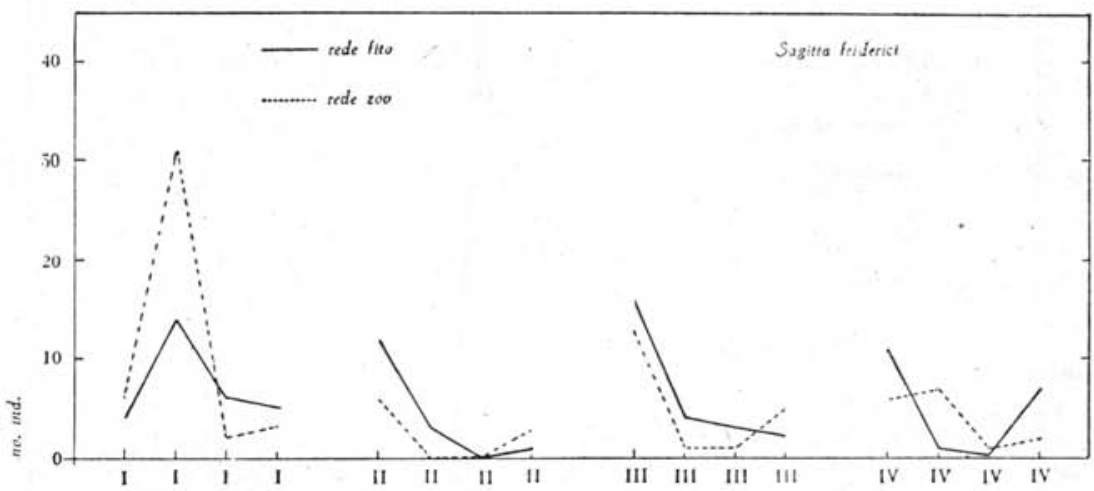

Fig. 11 - Quantidade de Sagitta friderici coletada pelas rêdes de * fitoplâncton e zooplâncton em cada estação.

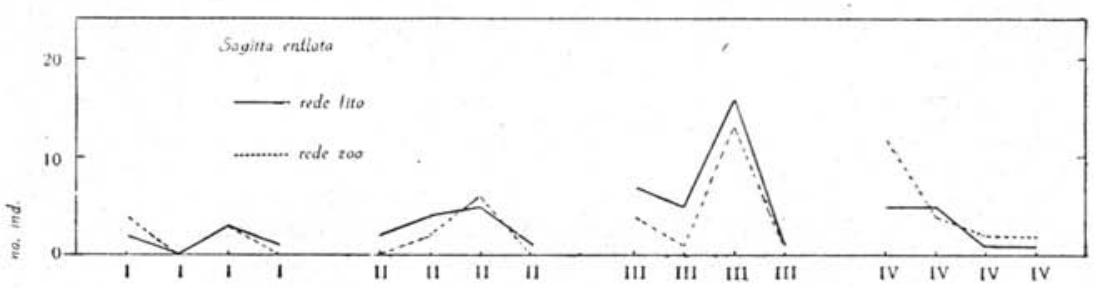

Fig. 12 - Quantidade de Sagitta enflata coletada pelas rêdes de fitoplâncton e zooplâncton em cada estação.

0 mesmo podemos dizer com relação às espécies de tamanho muito maior do que a malha da rêde, como Sagitta friderici e $S$. enflata. 
Pelos dados obtidos há indicações de que a rêde de fitoplâncton seleciona positivamente apenas os organismos pequenos, pertencentes ao primeiro grupo, e que os maiores, pertencentes aos segundo e terceiro grupos não sofrem seleção nem pela rêde de fito nem pela de zooplâncton. Acrescentamos ainda que a capacidade de movimentação dos animais parece não ter influência na seletividade dos mesmos.

Não só o tamanho é importante na seletividade dos animais pela rêde de plâncton, mas também a forma, porque esta pode impedir que um animal menor do que a malha da rêde a atravesse. Saville $(1958$, p. 197) verificou em seus experimentos que as espécies de Oithona foram mais retidas do que as outras espécies maiores, e atribuiu isso ao fato delas conservarem sempre as suas antenas estendidas lateralmente. Wiborg (1948, p. 11) também observou que as dimensões de um copépodo variam com a posição dos apêndices.

Saville (1958, p. 201) cita ainda, entre outros fatôres que influem na seleção dos animais planctônicos durante a coleta, a capacidade de compressão dos animais e a flexibilidade das malhas da rêde.

Devemos admitir portanto, que mesmo as espécies cujos indivíduos são um pouco maiores do que as malhas da rêde não são totalmente retidos por ela.

Gibbons (1939, p. 243) e Wiborg (1948, p. 6) citaram um outro fator que ocorre comumente: o entupimento das rêdes por algas e animais planctônicos. Segundo Wiborg (op. cit.) êste efeito não só diminui o tamanho da malha como também dificulta a filtração de água e se dá com maior ou menor intensidade, dependendo da natureza do plâncton coletado, isto é, onde há grande quantidade de fitoplâncton, o entupimento é maior.

\section{AS RELAÇOES DO PLÂNCTON COM AS MASSAS DE ÁGUA}

Os dados com os quais contamos neste trabalho foram suficientes sòmente para relacionar a ocorrência e abundância das espécies com as massas de água (Tabela I). Nenhuma relação, entretanto, foi encontrada quando consideramos o plâncton total.

O fitoplâncton, embora pouco abundante, foi representado por algumas espécies de Dinoflagelados e Diatomáceas (Tabela II).

Ceratium spp. e Pyrocystis pseudonoctiluca foram os mais abundantes, principalmente nas três últimas séries de amostras, isto é, em presença de água de plataforma. 
Coscinodiscus apareceu apenas nas duas últimas séries de amostras, mas em grande quantidade sòmente na última.

Ethmodiscus gazellae ao contrário, só estêve presente nas duas primeiras séries de amostras.

O zooplâncton desta região é constituído, principalmente, por espécies (Tabela II) neríticas. Em trabalhos anteriores, sôbre a distribuição de alguns grupos de animais planctônicos (Hydromedusae, Copepoda, Chaetognatha), foram assinaladas muitas das espécies que aqui compareceram nestas mesmas massas de água.

Hydromedusae - Tôdas as espécies aqui encontradas já foram assinaladas por Vannucci (1957), como típicas de água costeira ou de região lagunar. Algumas destas podem ser também encontradas em águas de plataforma e tropical, porém em menor quantidade. A ocorrência de Eucheilota duodecimalis foi registrada por Vannucci (1960, p. 395), na costa brasileira, na região de Cananéia, principalmente em água costeira de salinidade até $35,00 \%$ e de temperatura variando entre 25 e $28^{\circ} \mathrm{C}$. Todos os dados relativos às medusas obtidos através dêste material concordam com os de Vannucci (1957). Nenhuma das espécies dêste grupo foi abundante. Clytia cylindrica foi mais freqüente em águas tìpicamente costeiras.

Copepoda - A grande maioria dos organismos dêste plâncton é constituída por copépodos. Dentre êles, as espécies mais abundantes foram as seguintes: Oithona nana, Corycaeus giesbrechti, Paracalanus sp., Euterpina acutifrons e Temora stylifera.

Muitas das espécies de copépodos presentes neste material, já foram assinaladas por Björnberg (1959) como típicas de águas costeira ou de plataforma.

Das seguintes espécies, Acartia lilljeborghi, Eucalanus monachus, E. subcrassus e Calocalamus styliremis, sòmente raros indivíduos estiveram presentes em algumas das amostras da primeira série de coletas. Nas três últimas séries de amostras, compareceram em tôdas elas, porém sempre em pequena quantidade, indicando portanto uma preferência por águas de plataforma.

Calocalanus pavo compareceu em tôdas as amostras, sempre foi porém pouco numerosa.

Centropages furcatus também compareceu em tôdas as amostras, mas foi um pouco mais abundante em água costeira, entretanto, Björnberg (1959, p. 137) encontrou-a sòmente em águas de plataforma. 


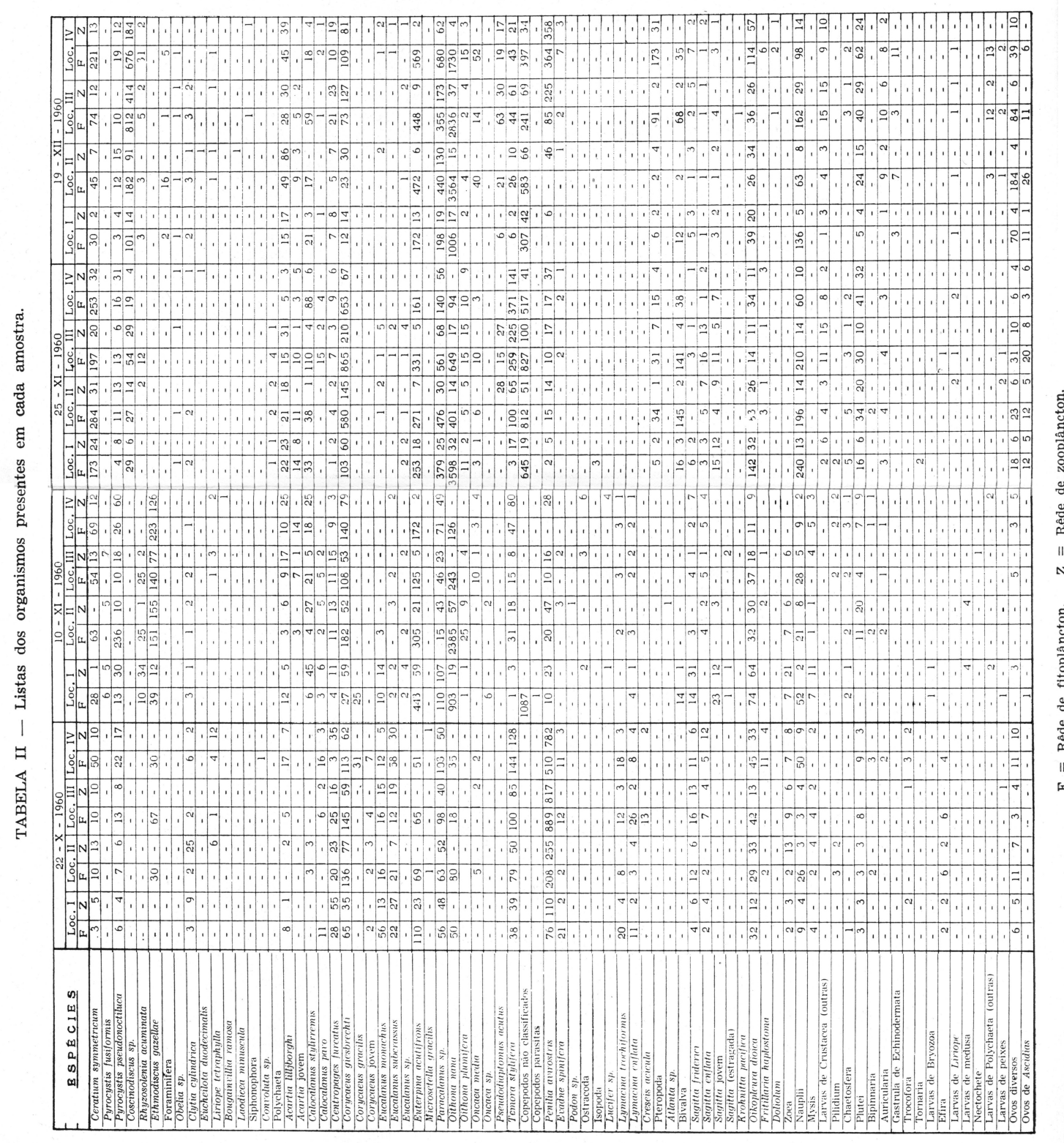


Em quase tôdas as amostras Corycaeus giesbrechti, Euterpina acutifrons, Oithona nana e Paracalanus sp. foram as espécies predominantes, Euterpina acutifrons e Oithona nana só não estiveram presentes em algumas amostras provenientes de água costeira. Tôdas elas mostraram uma nítida afinidade pela água de plataforma. Corycaeus giesbrechti foi encontrada também em grandes porcentagens por Björnberg ( $l$. c.) nesta massa de água.

Encontramos Temora stylifera em tôdas as amostras, e em algumas ela ocorreu em grande quantidade. Não apresentou, entretanto, uma preferência marcada por uma das massas de água.

Corycaeus gracilis, Oithona plumifera e Oncaea media foram representadas apenas por alguns exemplares.

Pseudodiaptomus acutus sòmente estêve presente nas duas últimas séries de coletas, não comparecendo em água costeira típicas, embora dados anteriores indiquem que esta espécie vive em águas de baixa salinidade. Segundo Jacobi (1953, p. 14) tôda a família Diaptomidae é característica de água doce e salobra. Marsh (1933, p. 30) assinala a presença de Pseudodiaptomus acutus em águas salobras da desembocadura do rio Amazonas.

Entre as espécies de Cladocera que ocorreram neste material, a que predominou foi Penilia avirostris. Compareceu em quase tôdas as amostras de água costeira, todavia, foi relativamente abundante em duas coletas da última série, em água de plataforma.

Outros crustáceos, tais como Ostracoda, Isopoda, Decapoda, compareceram neste material, porém em número muito reduzido.

Os moluscos foram representados neste material, por Bivalvia, Pteropoda e Heteropoda que, entretanto, nunca foram muito abundantes.

Tivemos neste material, três espécies de Chaetognatha, Sagitta friderici, S. enflata e Krohnitta pacifica. S. friderici é associada à água costeira e $S$. enflata à água de plataforma, mas também podem, tanto uma como outra, ocorrer na outra massa de água (Almeida Prado, 1961, p. 32). A presença de $S$. enflata e $S$. friderici concorda portanto, com os dados anteriores. Quanto a Krohnitta pacifica não temos ainda idéia definitiva das suas relações com salinidade e temperatura, porém já a encontramos em água costeira e de plataforma.

Duas espécies de Copelata ocorreram neste material, Oikopleura dioica e Fritillaria haplostoma. A primeira estêve presente em tôdas as coletas e em maior quantidade nas amostras de água costeira, com exceção de uma única coleta. A segunda foi repre- 
sentada apenas por alguns exemplares. Êstes dados vêm confirmar os achados de Forneris *, em que Oikopleura dioica demonstra preferência por água costeira e que Fritillaria haplostoma raramente é encontrada nesta massa de água.

Outros grupos, tais como Foraminifera, Turbellaria e Thaliacea ocorreram neste plâncton, porém com uma freqüência muito baixa.

Larvas - Como êste plâncton foi coletado próximo à costa, encontramos uma variedade muito grande de larvas de invertebrado, assim como algumas larvas de peixe. Os nauplii foram os mais abundantes, principalmente, nas duas últimas séries de amostras. Podemos atribuir êste aumento de nauplii à época destas coletas, pois temos encontrado em diversos anos uma grande quantidade de larvas no verão.

Outras larvas de crustáceos também ocorreram em quase tôdas as amostras, ainda que em pequenas quantidades. As larvas de Echinodermata que compareceram neste plâncton foram Auriculariae, Bipinnariae e Plutei, e êstes últimos foram freqüentes e relativamente abundantes.

Éfiras de medusas só foram encontradas na primeira série de coletas, em água costeira.

Ovos de Ascidia foram relativamente abundantes neste material e ocorreram sòmente nas duas últimas séries de coletas.

Tentamos, neste trabalho, relacionar os animais com as massas de água, mas nem sempre foi possível fazê-lo por várias razões.

Primeiramente, devemos considerar que a área pesquisada é uma enseada aberta para o alto-mar, e por isso, as massas de água estão sujeitas de um lado, às influências decorrentes de sua localização próxima à costa, e de outro a intenso intercâmbio com água da plataforma. Assim sendo, os ventos, chuvas e outros fatôres ocasionam grandes e rápidas modificações na hidrografia da região. Tôdas essas alterações influem, direta ou indiretamente, na composição do plâncton.

Concluindo, podemos dizer que o plâncton desta região é nerítico, isto é, a sua composição qualitativa e quantitativa é provàvelmente condicionada mais pela localização da área da qual provém, do que pelas massas de água.

* Forneris, L. - São Paulo, Inst. Ocean. 1961 (Comunicação verbal). 


\section{AGRADECIMENTOS}

Apresentamos aquí os nossos agradecimentos à Dra. M. Vannucci e ao Dr. I. Emílsson pela orientação dada ao presente trabalho, ao Sr. J. Tundisi pela determinação de grande parte do material e contagem de tôdas as amostras, à Dra. T. K. S. Björnberg pela classificação de alguns copépodos e aos Srs. A. Garcia Occhipinti e Clóvis Teixeira pelas sugestões dadas. Agradecemos ainda ao Sr. C. del Rio Garcia pela confecção dos gráficos e tabelas. Finalmente, somos gratos a todos os colegas que, de um modo ou de outro, tornaram possível a elaboração dêste trabalho.

\section{RESUMO}

O presente trabalho é um estudo do plâncton da enseada do Mar Virado (Fig. 1) sob seus aspectos mais gerais. $O$ plâncton foi coletado quatro vêzes em quatro estações dispostas em linha reta, nos meses de outubro, novembro e dezembro de 1960 (Tabela I). Foram feitas coletas verticais com duas rêdes de fito e zooplâncton, ambas das mesmas dimensões.

Primeiramente, fizemos o estudo da composição quantitativa do plâncton. Relacionamos a quantidade de plâncton com as estações oceanográficas (Fig. 2), datas de coleta, massas de água e outras condições do meio ambiente. Obtivemos os seguintes resultados: a quantidade de plâncton parece ser maior na Estação I e diminuir nas II, III e IV, isto é, maior em água costeira e menor em água de plataforma. Para o fitoplâncton obtivemos um resultado oposto, isto é, foi sempre mais abundante na presença de água de plataforma (Figs. 3-4).

Em seguida, fizemos uma análise comparativa das amostras coletadas com rêde de fitoplâncton e de zooplâncton. Baseados nesta análise, verificamos que a rêde de fitoplâncton seleciona positivamente apenas os animais de pequeno porte, e que os organismos maiores não sofrem seleção nem pela rêde de fitoplâncton nem pela de zooplâncton (Figs. 5-12).

Finalmente, fizemos um estudo das relações dos organismos planctônicos (Tabela II) com o meio ambiente, especialmente no que diz respeito ao zooplâncton e concluimos que êste é essencialmente nerítico.

\section{SUMMARY}

This paper presents the results of a series of investigations made on plankton samples (Table I) taken from October to December 1960 in the "Enseada do Mar Virado" (State of São Paulo, Brazil) (Fig. 1). The samples were studied under their general aspect. Four stations were occupied along a line at four different occasions. At each, samples were taken by means of vertical hauls with two similar plankton nets $25 \mathrm{~cm}$ wide at the mouth, one called "phytoplankton mesh" ( $1 \mathrm{~mm}$ wide apertures) and the other "zooplankton mesh" ( $3 \mathrm{~mm}$ wide apertures).

First, a study on the quantitative composition of the plankton was carried out. A relationship was established between the amount of plankton and the oceanographic station (Fig. 2), date of hauls, water masses and other environmental conditions. The following results were obtained: the amount of plankton seems to be greater in Station I than in Station II, III and IV, which means that the amount of plankton was greater in coastal than in shelf waters. Phytoplankton on the contrary, was always more abundant in shelf waters (Figs. 3, 4). 
A comparative analysis was made of the samples taken with phytoplankton and zooplankton meshes. It was verified that the phytoplankton mesh really selects only small animals and that larger organisms are not retained by any of them (Figs. 5-12).

Finally a study on the relationship between the planktonic animals (Table II) and the habitat, especially in what concerns the zooplankton, revealed that the latter is essencially neritic.

\section{BIBLIOGRAFIA}

Almeida Prado, M. S.

1961. Distribuição dos Chaetognatha no Atlântico Sul Ocidental. Bol. Inst. Ocean., vol. 11, n. $^{\circ} 4$, p. 15-49, grafs. tabs.

BJöRNBERG, T. K. S.

1959. Copepods as indicators of water masses off the Brazilian coast. Biogeography and environmental influences. Preprints Intern. Ocean. Congr., I, p. 137-138.

EMílsSON, I.

Levantamento oceanográfico-meteorológico da enseada do Mar Virado, Hidrologia. Contr. Avul. Inst. Ocean., Ocean. Fis. (No prélo).

GibBons, S. G.

1939. The Hensen net. Jour. Cons. Int. Explor. Mer, vol. 14, p. $242-248$.

ЈАКоBI, $\mathrm{H}$.

1953. Sôbre a distribuição da salinidade e do $\mathrm{pH}$ na baía de Guaratuba. Arq. Mus. Paranaense, vol. 10, p. 3-35.

Marsh, C. D.

1933. Synopsis of the calanoid crustaceans, exclusive of the Diaptomidae, found in fresh and brackish waters, chiefly of North America. Proc. U. S. Nat. Mus., vol. 82, p. 1-58.

Saville, A.

1958. Mesh selection in plankton nets. Jour. Cons. Int. Explor. Mer, vol. 23, n. $^{\circ} 2$, p. $192-201$.

VANNuCCI, M.

1957. On Brazilian Hydromedusae and their distribution in different water masses. Bol. Inst. Ocean., vol. 8, n. $^{\circ} 1 / 2$, p. 23-109.

1960. On the young stage of Eucheilota duodecimalis (Leptomedusae). An. Acad. Bras. Ciên., vol. 32, n. ${ }^{\circ}$ 3/4, p. 395-397.

WIBORG, K. F.

1948. Experiments with the Clarke-Bumpus plankton sampler and with a Plankton Pump in the Lofoten Area in Norway. Fiskeridir. Skr., Ser. Havunders., vol. 9, n. ${ }^{\circ}$ 2, p. 1-32. 